\title{
Lexical and sublexical orthographic processing: An ERP study with skilled and dyslexic adult readers
}

\author{
Susana Araújo a,b,*, Luís Faísca ${ }^{a}$, Inês Bramão ${ }^{c}$, Alexandra Reis ${ }^{a}$, Karl Magnus Petersson a,d,e \\ ${ }^{a}$ Cognitive Neuroscience Research Group, Department of Psychology, E Centre for Molecular and Structural Biomedicine, CBME/IBB, Portugal \\ ${ }^{\mathrm{b}}$ Faculty of Psychology \& Center for Psychological Research, University of Lisbon, Portugal \\ ${ }^{\mathrm{c}}$ Department of Psychology, Lund University, Lund, Sweden \\ ${ }^{\mathrm{d}}$ Max Planck Institute for Psycholinguistics, Nijmegen, The Netherlands \\ e Donders Institute for Brain, Cognition and Behaviour, Radboud University, Nijmegen, The Netherlands
}

\section{A R T I C L E I N F O}

Article history:

Accepted 12 November 2014

\section{Keywords:}

Dyslexia

ERPs

Orthographic processing

Phonological processing

\begin{abstract}
A B S T R A C T
This ERP study investigated the cognitive nature of the P1-N1 components during orthographic processing. We used an implicit reading task with various types of stimuli involving different amounts of sublexical or lexical orthographic processing (words, pseudohomophones, pseudowords, nonwords, and symbols), and tested average and dyslexic readers. An orthographic regularity effect (pseudowords-nonwords contrast) was observed in the average but not in the dyslexic group. This suggests an early sensitivity to the dependencies among letters in word-forms that reflect orthographic structure, while the dyslexic brain apparently fails to be appropriately sensitive to these complex features. Moreover, in the adults the N1-response may already reflect lexical access: (i) the N1 was sensitive to the familiar vs. less familiar orthographic sequence contrast; (ii) and early effects of the phonological form (words-pseudohomophones contrast) were also found. Finally, the later N320 component was attenuated in the dyslexics, suggesting suboptimal processing in later stages of phonological analysis.
\end{abstract}

(c) 2014 Elsevier Inc. All rights reserved.

\section{Introduction}

Fast visual word processing ability must rely on a perceptual mechanism especially tuned to the recurrent properties of the orthographic code, which allows for a direct translation from visual-orthographic codes into pronunciations (phonology) and word meaning (semantics) (Dehaene, 2010). Letter knowledge plays a major role in the emergence of this specialized mechanism for processing orthographic material, as suggested by neural correlates in illiterate vs. literate adults (Dehaene et al., 2010), children with basic (Brem et al., 2010) or with high letter-sound knowledge (Maurer, Brem, Bucher, \& Brandeis, 2005), and in adults trained on a novel script (Maurer, Blau, Yoncheva, \& McCandliss, 2010). One of the most reliable examples is that a neural region within the left ventral occipitotemporal cortex (vOT) shows preferential processing (i.e. stronger activation) to visually presented letter strings compared with a variety of control stimuli (the putative Visual

* Corresponding author at: Cognitive Neuroscience Research Group, Department of Psychology and Educational Sciences, \& Centre for Molecular and Structural Biomedicine, CBME/IBB, Campus de Gambelas, Universidade do Algarve, 8005-139 Faro, Portugal. Fax: +351 289800067.

E-mail address: smaraujo@ualg.pt (S. Araújo).
Word Form Area, Cohen et al., 2002; McCandliss, Cohen, \& Dehaene, 2003).

Letter-specific processing is also signaled by the N1 (or N170) electrophysiological component related to reading expertise (Helenius, Tarkiainen, Cornelissen, Hansen, \& Salmelin, 1999; Maurer et al., 2005, 2006). The N1 is a negative deflection peaking at approximately $150-200 \mathrm{~ms}$ post stimulus onset, which is significantly enhanced to orthographic strings (vs. non-orthographic items like symbols) in the left occipitotemporal region (e.g., Bentin, Mouchetant-Rostaing, Giard, Echallier, \& Pernier, 1999; Brem et al., 2009; Maurer et al., 2005; for an overview, see Maurer \& McCandliss, 2007), and might therefore be a neural index of the reduced specialization for written word processing in reading disorders like dyslexia. Similar effects have been found in the preceding P1 component ( 50-150 ms; e.g., Maurer et al., 2005, 2011) and the early P1-N1 peak(s) might reflect a reorganization of the brain that occurs as a function of reading training. For example, in a longitudinal study Maurer et al. (2007) demonstrated that over the course of kindergarten to the second grade, there is an increased activation in response to visual words that occurs around 150-270 ms. Recently, N1 difference in the ERPs between words and false-font strings was found by the end of the first grade, both at the group and individual response level (Eberhard-Moscicka, 
Jost, Raith, \& Maurer, 2014). Moreover, another result supporting the claim that the $\mathrm{N} 1$ reflects a specific brain training effect comes from studies with populations of different reading expertise: the $\mathrm{N} 1$ response is attenuated in groups lacking reading expertise such as dyslexic children (Araújo, Faísca, Bramão, Petersson, \& Reis, 2012; Hasko, Groth, Bruder, Bartling, \& Schulte-Körne, 2013; Maurer et al., 2007) and adults (Helenius et al., 1999; Mahé, Bonnefond, Gavens, Dufour, \& Doignon-Camus, 2012). This finding indicates that perceptual coding of orthographic properties might be compromised in dyslexia, contributing to a deficient development of automatic and fluent reading.

Yet, there is controversy about N1 specificity in the visual word recognition process, i.e. which specific properties of words triggers this effect in the N1 component, which we investigate in the present study. Does the N1 response only reflect perceptual expertise for letter recognition or is it also sensitive to sublexical orthographic structure and lexical properties of words? For the purpose of the present study we will consider that processing orthographic information includes both a low-level specialization for letters ("coarse tuning", as for example reflected by contrasts between letters strings and pseudofonts or symbol strings) and an orthographic sensitivity at sublexical and whole-word level ("fine tuning"). Orthographic processing at the sublexical level is intimately connected to the ability to process the general attributes of the writing system such as sequential dependencies and letter position frequencies, while coding of orthographic information at the whole-word level is based on the ability to represent the unique array of letters that defines a printed word (see for example Burt, 2006; Hagiliassis, Pratt, \& Johnston, 2006).

Previous research addressing the effects of orthographic familiarity and lexicality on the very early ERP responses has been inconsistent. One set of studies described similar brain activation patterns for words and pseudowords observed around the peak of the N1 (Araújo et al., 2012; Bentin et al., 1999; Hasko et al., 2013; Kast, Elmer, Jancke, \& Meyer, 2010; Maurer et al., 2005), and no modulation by different levels of word frequency (Araújo et al., 2012). These findings suggest that the N1-evoked response might arise at the earliest prelexical stages of the orthographic system. However, there are also reports of $\mathrm{N} 1$ sensitivity to higher language functions, including the recognition of familiar patterns of letters within visual word-forms. Some studies did find significant lexicality effects at early latencies encompassing this ERP component, with pseudowords eliciting stronger brain activity than words (Hauk et al., 2006; Sereno, Rayner, \& Posner, 1998), and also larger amplitudes in response to low-frequency compared with high-frequency words (Assadollahi \& Pulvermuller, 2003; Hauk et al., 2006; Sereno et al., 1998). These findings have commonly been interpreted as reflecting a facilitated access to lexical orthographic information for familiar words between 100 and $200 \mathrm{~ms}$. Finally, other studies have described an effect of orthographic sublexical regularity as early as $100 \mathrm{~ms}$, and localized into left inferior temporal areas (Coch \& Mitra, 2010; Hauk et al., 2006). For example, atypical items quantified by bigram or trigram frequencies elicit more brain activity than typical ones (Hauk et al., 2006), which suggests that orthographic structure processing is under way at this time frame; but other measures of orthotactic dependencies such as sequential constrains still need to be tested.

To summarize, the involvement of the N1 component in early visual word processing has been established, but as yet its specificity during orthographic processing remains an open question. One way to approach this question in the current study was by manipulating various types of stimuli that involve different amounts of sublexical or lexical variants of orthographic processing: symbol strings, real words, pseudohomophones, pseudowords and nonwords. To provide a complete scenario, we further manipulated reading competence, so average and impaired dyslexic readers were compared as a between-subject factor. In the recent years, an increasing number of studies have provided evidence for a failure in orthographic processing in dyslexia, as expressed by behavioral (Araújo, Faísca, Bramão, Petersson, \& Reis, 2014; Bergmann \& Wimmer, 2008; Marinelli, Angelelli, Notarnicola, \& Luzzatti, 2009; Marinus \& de Jong, 2010) and neural correlates such as dyslexic vOT under activation (Hawelka, Gagl, \& Wimmer, 2010; Maurer et al., 2007, 2011; van der Mark et al., 2009; Wimmer et al., 2010) or absent modulations of N1 responses to letter strings vs. symbols (Maurer et al., 2007). Considering previous interpretations of impaired vOT orthographic processing in dyslexia as a tuning deficit at sublexical or lexical level (Richlan et al., 2010; van der Mark et al., 2009; Wimmer et al., 2010), we would expect a condition-specific group effect in N1 waveform as well, depending on whether this component reflects processing at these levels (since selective responses to letters in the $\mathrm{N} 1$ time window most likely originate from the inferior occipitotemporal cortex; Maurer \& McCandliss, 2007; Tarkiainen, Helenius, Hansan, Cornelissen, \& Salmelin, 1999).

Hence, in this study ERPs were recorded during an implicit reading task in order to (1) distinguish the effect of the sublexical orthographic properties from the whole-word orthography on P1/ $\mathrm{N} 1$ neural responses in normal adult readers and dyslexic readers, and to (2) clarify whether group differences in orthographic processing efficiency can be somewhat traced to these processing levels. First, the N1 coarse specialization for letter strings was indexed by the ERP difference between pseudowords and symbolsequences. This difference provides information on specific brain letter effects ("tuning to letter strings"), as both types of stimulus mainly differ with respect to the amount of letter-specific processing that is required. Next, the sublexical orthographic effect was indexed by the ERP difference between pseudowords (orthographically legal) and nonwords (containing at least one illegal letter bigram). Neither pseudowords nor nonwords have entries in the readers' mental lexicon, so the effect of lexical-level knowledge is controlled. Hence, the prominent difference that emerged relates to their sublexical orthographic structure in terms of orthotactic constraints (i.e., violates the sequential dependencies among letters and positions within word-forms, or not). Finally, we examined whether early ERP responses in the P1 and N1 ranges were sensitive to lexicality by contrasting familiar words, pseudowords and pseudohomophones. Comparing words with pseudowords or pseudohomophones serves to contrast information on the structure of a word-form while controlling for letter expertise. Familiarity differences between pseudowords and real words are not restricted to the visual-orthographic appearance of word-forms but also to the corresponding phonology, but by including pseudohomophones - phonologically familiar but spelled incorrectly we minimize any potential phonological familiarity confounds (i. e., for the contrast words - pseudohomophones, differences in phonology cannot account for ERP modulations because the stimulus types can only be distinguished by the whole-word orthography). If these stimulus categories produce different $\mathrm{N} 1$ responses, this provides evidence of a $\mathrm{N} 1$ sensitivity at the level of accessing specific word-form representations in memory. For example, if topdown linguistic information related to whole-word orthography shapes early orthographic processing indexed by the $\mathrm{N} 1$, then real words should elicit lower ERP amplitudes than the pseudowords and the pseudohomophones because only the former have matching orthographic word entries. In contrast, a similar activation across stimulus types suggests that perceptual expertise for words indexed by the N1 is strictly associated with early stages of letter detection in prelexical orthographic processing.

In turn, whether dyslexic subjects are impaired at any of these orthographic processing levels, this should be reflected in deviations from the moment that ERPs are modulated by sublexical 
and lexical effects (i.e., no ERP differences as a function of stimulus type, unlike controls). Finally, because phonological processing difficulty is a core feature of dyslexia (underspecified or/and less accessible phonetic representations in dyslexics; e.g., Boets et al., 2013; Ramus et al., 2003; for a review, see Ramus \& Szenkovits, 2008), in this study we also analyzed the later N320 component that has been implicated in phonologic processing (e.g., Bentin et al., 1999; Simon, Bernard, Largy, Lalonde, \& Rebai, 2004) for group differences. We predicted that phonological effects will be observed somewhat later in processing, for example, the assembly of a new pronunciation would presumably be more difficult for nonwords as compared to pseudowords, and so larger negativities should be elicited for pseudowords in the N320 range. Most of the studies on phonological processing in impaired reading have employed indirect meta-phonological awareness tasks like rhyme judgments. In this study we used a more natural reading context and are thus better able to address the online phonological processing in dyslexia.

\section{Material and methods}

\subsection{Participants}

Fifteen adults with developmental dyslexia ( 5 males and 10 females; mean age $[ \pm S D]=23.9[ \pm 4.9]$ years) and 19 matched controls ( 7 males and 12 females; mean age $[ \pm S D]=23.7[ \pm 4.3]$ years) were tested in this study. All were native speakers of Portuguese and, apart from two participants, were undergraduate students; none of them reported neurological diseases or psychiatric disorders. The dyslexic participants volunteered to take part in the study through advertisement on the University e-mail services and campus posters. All had received a formal dyslexia diagnosis by a specialized therapist during their childhood/adolescence and still considered their reading speed and spelling inadequate. Control participants had no history of reading and/or spelling problems. All participants completed a battery of reading and cognitive tests for dyslexia, described below. In addition, participants completed the Portuguese adaptation of the Adult Reading History Questionnaire (QHL; Lefly \& Pennington, 2000), which is a reliable tool for dyslexia screening (Alves \& Castro, 2004). Written informed consent was provided for each participant in compliance with the Helsinki Declaration.

The individual's reading achievement was assessed through the time-limited reading aloud test, adapted for the Portuguese population from the Differential Diagnosis Dyslexia Battery (3DM; Blomert \& Vaessen, 2009). The reading test contained three subtasks of high- and low-frequency words and pseudowords (half a minute for each subtask); reading speed was taken as the number of correct items read per second. Because appropriate age norms were not available, reading scores were converted into z-scores with reference to normative data which was collected in a preliminary study with 177 adults (mean age $21.1 \pm 3.5$ ). Dyslexic participants' word reading scores were at least 1.5 standard deviation (SD) below the normative sample mean, while participants assigned to the control group had word reading scores in the range of $\pm 1 \mathrm{SD}$. A further inclusion criterion for all the participants was a nonverbal IQ in the normal range (>85; Wechsler Adult Intelligence Scale - WAIS-III). In addition to the Performance Scale subtests, two subtests (Vocabulary and Digit Span) of the WAIS-III Verbal Scale were also performed. Finally, phonological processing was assessed with a Phoneme deletion and Spoonerism task (Francisco \& Faísca, 2012), adapted from the ones developed by Venkatagiri and Levis (2007), and a Rapid automatized naming task with letters and digits (Phonological Assessment Battery; Alves, Branco, Pontes, \& Castro, 2007). As can be seen in Table 1 non-verbal IQ did not differentiate the groups, but the mean performance of the dyslexics was reliably lower than that of the controls for the digit span subtest, and for all reading and phonological processing tasks.

\subsection{Stimulus material}

The stimulus type was manipulated in five experimental conditions: (1) real words (W; orthographically and phonologically familiar Portuguese nouns), selected from the Corlex frequency database (Bacelar do Nascimento et al., 2007); (2) pseudohomophones (PH; phonologically familiar but orthographically unfamiliar forms of the same real words); (3) pseudowords (PW; orthographically plausible but phonologically unfamiliar); (4) nonwords (NW; orthographically illegal and phonologically unfamiliar); (5) and symbol-sequences (SS). The length of the real words varied from 4 to 8 letters (with exception of three items that had 10 letters), and only concrete nouns were included. Pseudowords were created in such a way that they have the same structure as real words. Nonwords were generated so as to contain at least one illegal letter bigram (e.g., fidumça; the letter sequence "mç" violates Portuguese orthographic rules, as the letter " $\mathrm{m}$ " can only be followed by the consonants "p" or " $b$ "). The four orthographic conditions (W, PH, PW, NW) were matched for number of letters, positional bigram frequency, and number of orthographic neighbors (based on the Corlex and Porlex Portuguese databases; $p>.2$ for all comparisons; Table 2). Lastly, in our study symbol strings were included as controls for letter strings of equivalent length, to make our data comparable to previous studies; the difference between letters strings (like words or pseudowords) and symbol strings has been widely investigated, and allows us to examine the "coarse specialization" for letters. For this condition, twentyone different non-orthographic symbols were selected and matched in length with the real words; a correspondence between letters and symbols was established and kept consistent (e.g., $\square \diamond \bigcirc \diamond)$. In total, 52 stimuli per condition were selected.

\subsection{Experimental procedures}

We used an implicit reading task in order to minimize effects related to task dependent decision or verification processes as, for example, in standard lexical decision tasks used elsewhere (e. g., Hauk \& Pulvermuller, 2004; Taroyan \& Nicolson, 2009). In this task, after the stimulus presentation, two alternative responses were displayed simultaneously on the screen: one letter/symbol that was presented in the previous stimulus and one letter/symbol that was not presented in the previous stimulus. The relative position of the letter/symbol in the stimuli was randomly determined. The subjects had to decide which of the two alternative responses was present in the preceding stimulus by pressing the corresponding response button (left or right shift). Hence, this task allowed ERPs to be calculated for each stimulus on its initial presentation without interference from any reaction on the part of the subject, while behavioral responses after stimulus presentation ensured that subjects were engaged in the task. Moreover, the same task was used in a previous study with children (Araújo et al., 2012), proving to be suitable for testing the reading-related N1 specialization.

The 260 stimuli were presented in two pseudorandomized lists, and each list was divided into five blocks of 26 items each. Conditions were balanced within blocks and each stimulus was presented only once. When creating the two lists we ensured that the order of real words and corresponding pseudohomophones was counterbalanced: In List 1 the real word was presented before the corresponding pseudohomophone in half of the cases and the opposite for the other half. In List 2 the order was reversed. The presentation order of the lists was counterbalanced across subjects. Presentation software (version 0.7; nbs. neuro-bs.com/ 
Table 1

Average performance on cognitive tasks and mean age of dyslexic and control participants and group differences ( $t$-test).

\begin{tabular}{|c|c|c|c|c|c|}
\hline & \multicolumn{2}{|c|}{ Dyslexics $(n=15)$} & \multicolumn{2}{|c|}{ Controls $(n=19)$} & \multirow[t]{2}{*}{$t$-value } \\
\hline & M & SD & M & SD & \\
\hline Age (years) & 23.9 & 4.9 & 23.7 & 4.3 & -0.08 \\
\hline Non-verbal IQ & 104.5 & 9.9 & 105.9 & 7.7 & 0.45 \\
\hline Vocabulary & 9.9 & 2.5 & 11.2 & 2.2 & 1.57 \\
\hline Digit span & 9.1 & 2.8 & 11.6 & 1.9 & $3.04^{*}$ \\
\hline \multicolumn{6}{|l|}{ Reading speed (items/s) } \\
\hline Words & 1.2 & .31 & 1.9 & .18 & $8.37^{* *}$ \\
\hline Pseudowords & 0.8 & 0.2 & 1.5 & 0.2 & $8.32^{* *}$ \\
\hline Phoneme deletion (máx.18) & 12.8 & 2.8 & 16.4 & 2.2 & $4.16^{* *}$ \\
\hline Spoonerism (máx.38) & 20.5 & 12.4 & 32.1 & 5.2 & $3.38^{*}$ \\
\hline \multicolumn{6}{|l|}{ RAN (s/50 items) } \\
\hline RAN letters & 26.5 & 4.5 & 17.5 & 2.3 & $-7.53^{* *}$ \\
\hline RAN digits & 25.8 & 4.0 & 17.1 & 3.5 & $-6.73^{* * *}$ \\
\hline QHL (máx.100) & 67.6 & 9.0 & 25.4 & 7.8 & $-13.98^{* *}$ \\
\hline
\end{tabular}

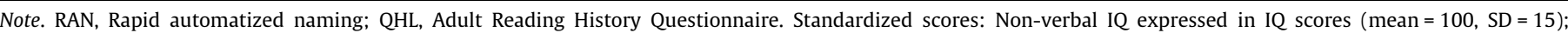
performance on the vocabulary and digit span tasks expressed in standardized scores $($ mean $=10, S D=3$ ).

${ }^{*} p<.01$.

$p<.001$.

Table 2

Means (standard deviations) for orthographic items characteristics.

\begin{tabular}{|c|c|c|c|c|}
\hline & W & $\mathrm{PH}$ & PW & NW \\
\hline Number of letters & $6.98(1.29)$ & $7.04(1.43)$ & $6.94(1.29)$ & $7.06(1.35)$ \\
\hline Bigram frequency & $40,597(18,528)$ & $40,143(25,081)$ & $41,343(24,388)$ & $41,722(28,597)$ \\
\hline Orthographic neighbors & $0.36(.68)$ & $0.42(.57)$ & $0.38(.63)$ & $0.42(.66)$ \\
\hline
\end{tabular}

Note. W, Words; PH, Pseudohomophones; PW, Pseudowords; NW, Nonwords.

presentation) was used to display the stimuli on a computer screen and to register the subject responses. All orthographic items were presented in lowercase ("Arial"; font size 47; black font on white background), at eye-level at the center of the screen, and ranged from $2.2^{\circ}$ to $3.8^{\circ}$ visual angle.

The trial sequence of events was as follows: first, a fixation cross $(+)$ was presented for $500 \mathrm{~ms}$ in the center of the screen; then, the stimulus was displayed for $2000 \mathrm{~ms}$, followed by the two alternative responses, which remained on the screen until the participant pressed a response button. The screen position of the correct responses was counterbalanced. The participants were encouraged to pause after each block. Before the task, the participants practiced ten trials to adequately familiarize themselves with the experimental task.

\subsection{ERP recordings}

Continuous electroencephalogram (EEG) was acquired through the ActiveTwo Biosemi electrode system from $64 \mathrm{Ag} / \mathrm{AgCl}$ active scalp electrodes that were mounted in an elastic cap. These electrodes were located at standard left and right hemisphere positions over the frontal, parietal, occipital, and temporal areas. They were also positioned according to the International 10-20 system guidelines. The electrode montage included 10 midline sites and 27 sites over each hemisphere. Two additional electrodes (CMS/DRL nearby $\mathrm{Pz}$ ) were used as an online reference (for a complete description, see biosemi.com; Schutter, Leitner, Kenemans, \& van Honk, 2006). Three other electrodes were attached over the right and left mastoids and below the right eye, to monitor eye movements and eye blinks. Bioelectrical signals were amplified using an ActiveTwo Biosemi amplifier (DC-67 Hz bandpass, $3 \mathrm{~dB} /$ octave) and were continuously sampled (24 bit sampling) at a rate of $512 \mathrm{~Hz}$ throughout the experiment.

\subsection{ERP data analysis}

The EEG data were analyzed using the FieldTrip open source toolbox (Oostenveld, Fries, \& Jensen, 2009; documentation and algorithms available at ru.nl/fcdonders/fieldtrip). ERP data were averaged over an epoch of $1125 \mathrm{~ms}$ (from $125 \mathrm{~ms}$ prior to until $1000 \mathrm{~ms}$ following the stimulus) and were time-locked to the onset of the stimuli. Trials containing ocular and/or muscle artifacts, or electric noise were excluded before averaging the trials. Moreover, only trials with correct responses were analyzed. Two controls and one dyslexic subject were not included in the ERP analysis due to a high percentage of artifacts (more than $30 \%$ of the trials per condition). Corrected trials were filtered offline ( $30 \mathrm{~Hz}$ lowpass) and rereferenced to average reference (eye electrodes were excluded to compute the common reference). ERP data were analyzed by computing the mean amplitudes of the waveforms during specific time windows, relative to the $125 \mathrm{~ms}$ pre-stimulus baseline. Individual ERPs were averaged within each experimental condition and for each group.

To restrict the number of statistical comparisons, electrodes were selected a priori in regions of interest according to theoretical considerations and visual inspection. To analyze the effects of letter-specific processing, we compared ERPs elicited by pseudowords with those elicited by symbol-sequences, during the time windows from 80 to $120 \mathrm{~ms}$ (P1 component) and from 150 to $180 \mathrm{~ms}$ (N1 component). Next, whether the P1 and N1 are sensitive to sublexical orthographic structure was assessed by comparing the ERPs to orthographically legal (i.e., pseudowords) with the ERPs to orthographically illegal (i.e., nonwords) non-lexical items. Finally, to examine whether these early components could already reflect orthographic familiarity at the whole-word level, we compared ERPs elicited by orthographic familiar (real words) with those elicited by orthographic unfamiliar (pseudohomophones and pseudowords) word-forms. For all these comparisons, 
responses in the $\mathrm{P} 1$ and $\mathrm{N} 1$ time windows were analyzed in three scalp regions: Frontal (F1/F2, FC1/FC2, FC3/FC4), parieto-occipital (P5/P6, P7/8, PO3/PO4, PO7/PO8), and occipital (01/O2).

Finally, we also identified prominent peaks in the ERP waveforms of the differences between pseudowords and nonwords at $\sim 180-220 \mathrm{~ms}, 250-300 \mathrm{~ms}$, and $310-350 \mathrm{~ms}$, with a maximum over more anterior temporal and temporo-parietal sites (T7/T8, TP7/TP8). Based on the latency and topographical distribution, the peak from 310 to $350 \mathrm{~ms}$ was identified as the N320 component, which has been consistently implicated in phonological processes (e.g., Bentin et al., 1999). Because these processes are at the core of reading problems in dyslexia, we were also interested in this later component.

\section{Results}

\subsection{Behavioral results}

The data were analyzed using a repeated-measures ANOVA with Stimulus Type as a within factor and reading Group as a between factor.

\subsubsection{Response time analysis}

Response times (RTs) from the incorrect answers and implausibly long or short RTs (i.e., 2.5 SD below or above the subject and condition means) were excluded from the analysis. Mean RTs were calculated for each subject and each condition. A significant main effect of Group on RTs, $F(1,32)=12.0, p<.005$, indicated that responses were generally slower for the dyslexic group $(1192 \pm 293 \mathrm{~ms})$ as compared to the controls $(917 \pm 164 \mathrm{~ms}$; Fig. 1). The effect of Stimulus Type was modulated by the factor Group, $F(2.27,77.57)=6.1, p<.005$. A post-hoc analyses revealed that the controls' responses were slower to SS compared to all orthographic conditions ( $p<.05$, for all comparisons), but the same difference failed to reach significance in dyslexics. Moreover, comparisons between groups revealed that the control group responded to orthographic items (W, PH, PW, and NW) significantly faster than the dyslexic group ( $p<.05$, for all comparisons), whereas no difference between groups was observed with the SS condition $(p=.92)$.

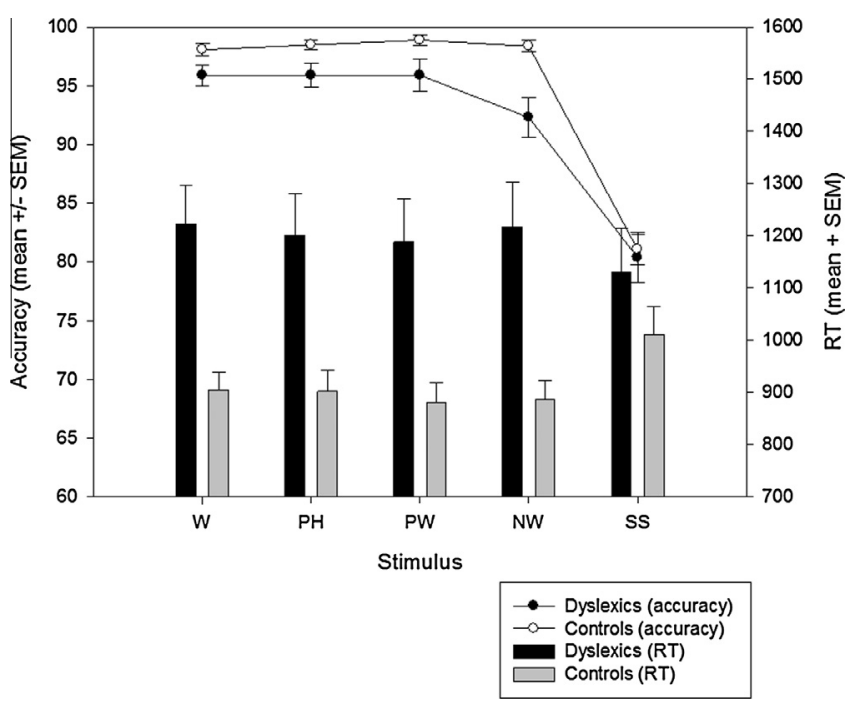

Fig. 1. Mean accuracy and response times for each stimulus type (W: real words, $\mathrm{PH}$ : pseudohomophones, PW: pseudowords, NW: nonwords, SS: symbol sequences) and for each group. The error bars represent standard error of the mean.

\subsubsection{Accuracy analysis}

A significant main effect of Group was observed, $F(1,32)=7.2$, $p=.012$. The subjects with dyslexia made relatively more errors in comparison with their respective controls (92\% and 95\% correct answers, respectively). A significant main effect of the Stimulus Type, $F(2.41,77.36)=134.1, p<.001$, and a marginally significant interaction between Group and Stimulus Type, $F(2.41,77.36)$ $=2.5, p=.077$, were also found. Both groups were less accurate to SS than to orthographic items ( $p<.001$, for all comparisons), and performed equally well in all the orthographic conditions. Comparisons between groups showed that dyslexics' responses were less accurate only for NW ( $p=.006$; Fig. 1).

\subsection{Electrophysiological results}

We first performed an overall analysis of variance on the mean amplitude of the P1, N1, and N320 components from the representative electrodes, with Stimulus Type (words vs. pseudohomophones vs. pseudowords vs. nonwords vs. symbols), Hemisphere (right vs. left) and Electrode Site as within-subject factors and Group as a between-subject factor. This overall analysis was done before testing the specific contrasts of interest in order to protect against Type I Error. Two- and three-way interactions involving group and stimulus type were found to be significant; therefore, we proceed to test our hypotheses and each contrast regarding our manipulation of interest was examined separately in a mixed-design ANOVA. The within-subject factors were again the Stimulus Type, Hemisphere, and - where applicable - Electrode Site, and the between-subject factor was Group. The Greenhouse-Geisser adjustments were employed to correct for violations of sphericity where necessary. Post-hoc analyses (Tukey HSD) were conducted here to investigate significant effects. We note that both ANOVAs resulted in very similar outcomes, including the same critical interactions. Therefore, the following discussion of results will focus on the contrast analysis.

\subsubsection{Early ERP components}

3.2.1.1. Letter-specific processing: comparison of orthographic (PW) and non-orthographic (SS) items. Letter processing includes a first visual processing stage during which letter features are extracted and integrated into percepts. To examine this "coarse" specialization for letter processing we investigated the pseudowords-symbols contrast as this isolates letter-specific processing.

P1 (80-120 ms). No stimulus type and no group or interaction effect was observed in the P1 range. Only a main electrode site effect was near significance $(F(2,58)=3.0 .7, p=.056)$ indicating more positive ERPs at parieto-occipital and occipital sites than at anterior, frontal sites.

N1 (150-180 ms). A significant stimulus type effect indicated that the N1 response in the ERPs was smaller for the PW than for the SS $(F(1,29)=7.3, p=.011$; Figs. 2 and 5$)$. Similar differences were found when we ran an ANOVA on the three other conditions with orthographic stimuli (i.e., W, PH, NW) vs. SS (for brevity, these contrasts are not reported here). The main effect of electrode site ( $F$ $(2,58)=72.6, p<.001)$ and hemisphere $(F(1,29)=5.0, p=.033)$ was also significant, because ERPs were more negative over the left posterior sites, as well as the interaction between electrode site and stimulus type $(F(2,58)=11.1, p<.001)$ and a marginally significant interaction between hemisphere and stimulus type $(F(1,29)=3.2$, $p=.083$ ). Lastly, the three-way interaction between electrode site, hemisphere, and stimulus type $(F(2,58)=6.8, p=.002)$ was significant. Post-hoc analyses revealed that, at occipital sites, the ERPs to SS were overall more negative than the ERPs to PW, while at parieto-occipital and anterior locations such effect was restricted to the right hemisphere. No group effect or interaction of group with stimulus type was observed. 

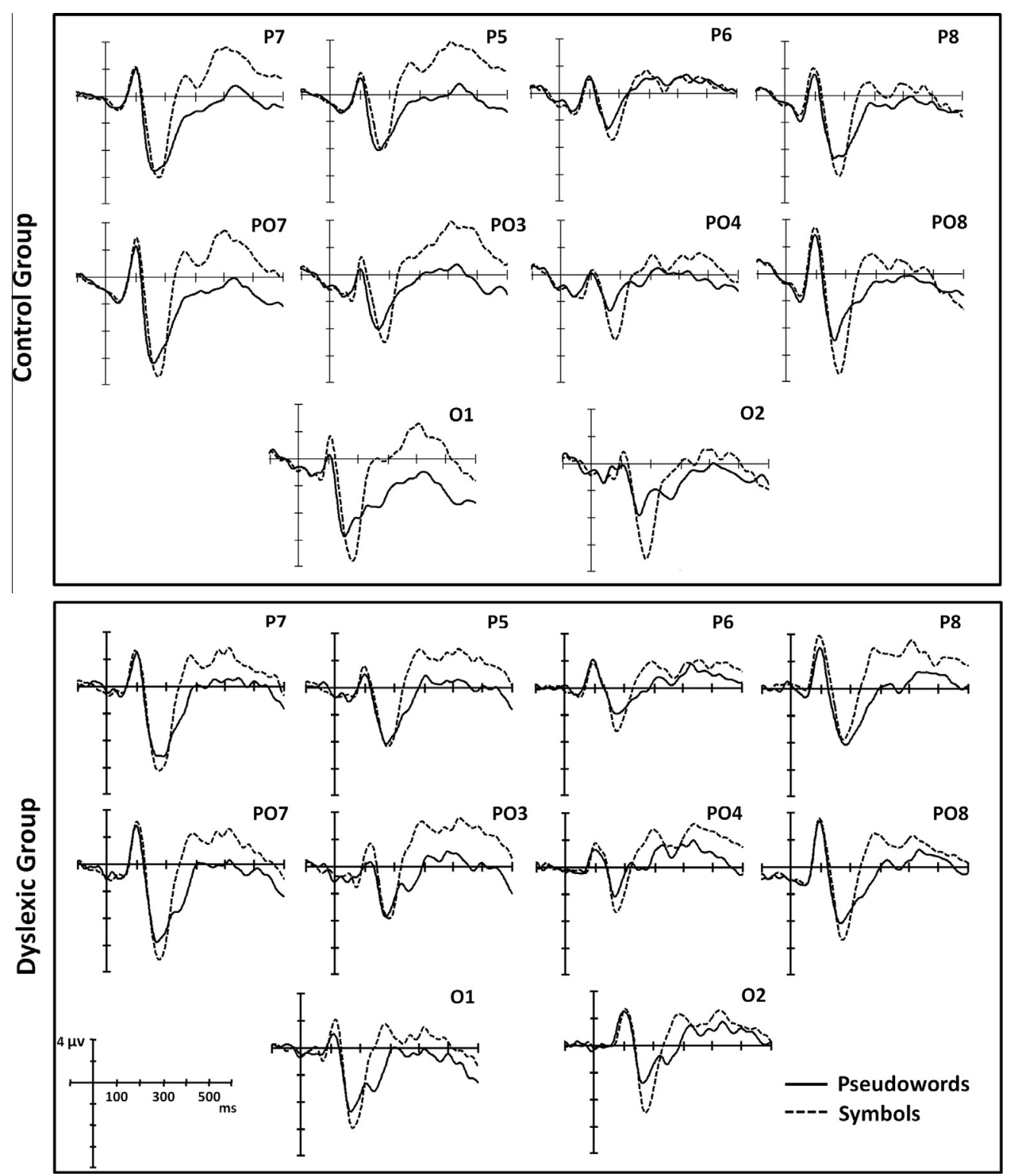

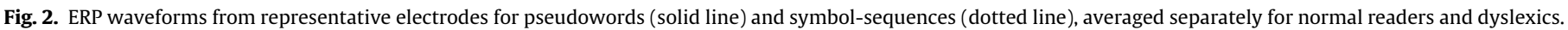

3.2.1.2. Comparison of orthographically legal (PW) with orthographically illegal (NW) non-lexical items. To investigate early effects of sublexical orthographic processing, we contrasted the brain activation to PW vs. NW, because the critical difference between these conditions is related to sublexical orthographic structure; here assessed by means of orthographic regularity.

P1 (80-120 ms). The ANOVA showed a significant effect of stimulus type $(F(1,29)=4.7, p=.038)$. During the P1 time window, the ERPs associated with NW were more positive than the ERPs associated with PW. This modulation was mainly observed at left posterior sites, as indicated by the three-way interaction (electrode site by hemisphere by stimulus type, $F(2,58)=3.8, p=.029)$. The three-way interaction stimulus type by electrode site by group $(F$ $(2,58)=4.1, p=.024)$ was also significant. Post-hoc analyses revealed that, at occipital sites, only the control readers differentiate processing of PW vs. NW $(p=.004)$, with NW associated with larger ERP amplitudes. Lastly, there was an interaction between group and hemisphere $(F(1,29)=5.1, p=.032)$ reflecting the fact that in the control group, the P1 mean peak amplitudes distributed symmetrically across hemispheres, whereas in the dyslexic group were more positive over the right than the left hemisphere $(p=.026)$. No other main or interaction effects were observed (Figs. 3 and 5 ).

N1 (150-180 ms). A significant main effect of electrode site ( $F$ $(2,58)=71.9, p<.001)$ and hemisphere $(F(1,29)=7.2, p=.012)$ was observed, as well as the interaction electrode site by hemisphere $(F(2,58)=9.5, p<.000)$. The observed interaction was due to the fact that at posterior sites, the ERPs were more negative over the left hemisphere than the right hemisphere $(p<.001)$, while at anterior, the ERPs showed bilateral activity. Additionally, there was a significant three-way interaction between stimulus type, electrode site and group $(F(2,58)=6.7, p=.002)$. Only the control readers differentiate processing of both stimulus types, i.e. showed significant larger negativities to PW (vs. NW) in occipital regions $(p=.018)$ that inverse in polarity in anterior regions $(p=.038)$ (Figs. 3 and 5). No additional effects or interactions were found.

3.2.1.3. Comparison of orthographic familiar $(W)$ with unfamiliar $(P H$, PW) word-forms. To test the P1-N1 sensitivity to whole-word orthography we contrasted ERPs to letter-strings that mainly differ 

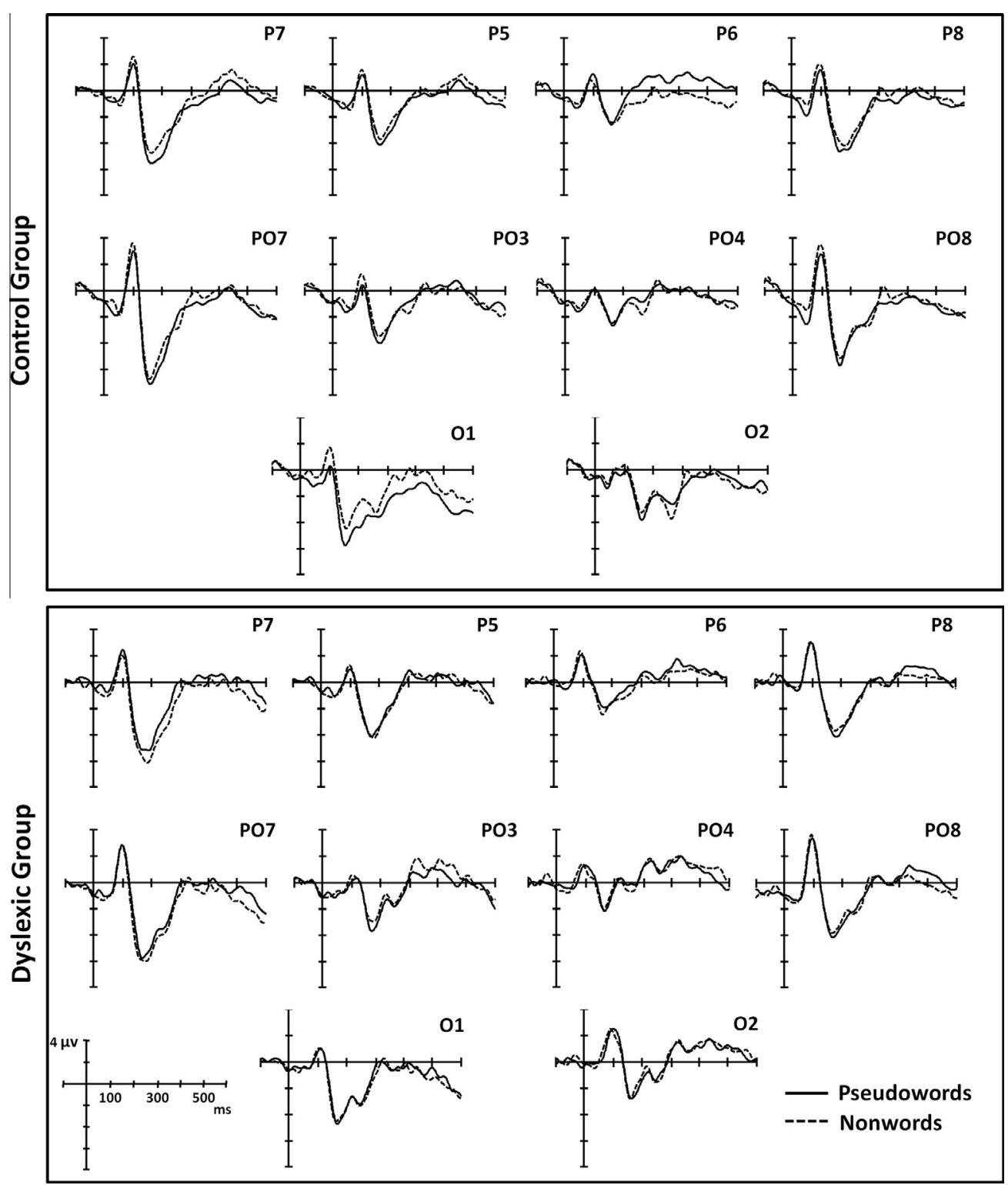

Fig. 3. ERP waveforms from representative electrodes for pseudowords (solid line) and nonwords (dashed line), averaged separately for normal readers and dyslexics.

in terms of orthographic familiarity at the lexical level, W vs. PH vs. PW.

P1 ( $80-120 \mathrm{~ms})$. The stimulus type interacted significantly with the factor hemisphere $(F(2,58)=4.0, p=.023)$ irrespective of group. Words $(\mathrm{W})$ were associated with greater positive amplitudes over the right hemisphere compared to PH $(p=.002)$ and PW $(p<.05)$; these items were not significantly distinct over the left hemisphere. The main effect of electrode site was also close to significance $(F(2,58)=2.4, p=.102)$ as stimuli tended to be more positive at posterior locations compared to frontal locations. Analyses also showed an interaction between group and hemisphere $(F$ $(1,29)=4.9, p=.036)$. In the control group, the frontal, parietooccipital and occipital sites exhibited bilateral asymmetry, whereas in the dyslexic group these sites showed rightward activity. No group or interaction between group and stimulus type was evidenced.

$N 1(150-180 \mathrm{~ms})$. A main effect of electrode site $(F(2,58)=77.3$, $p<.001)$ and hemisphere $(F(1,29)=4.8, p=.037)$, and an interaction electrode site by hemisphere $(F(2,58)=11.0, p<.001)$, indicated that ERPs were more negative over left posterior sites. An interaction between hemisphere and stimulus type $(F(2,58)=6.0$, $p=.004$ ) was also observed. Post-hoc analyses indicated that, at right posterior locations, the ERPs to $\mathrm{PH}$ were more negative than those to W and PW ( $p<.001$, for both comparisons), while stimuli did not differentiate at left posterior locations. However, when testing for differences separately at each electrode location, it was evident that at the left occipital sites the ERPs to $\mathrm{W}$ were as expected less negative than the ERPs to $\mathrm{PW}(p=.041)$ and $\mathrm{PH}$ $(p=.078)$, which did not differ from one another (interaction hemisphere by stimulus type, $F(2,58)=3.2, p=.046$; Figs. 4 and 5 ). Neither significant group main effect nor group by stimulus type interaction was evidenced.

\subsubsection{Late ERP components}

Lastly, because poor phonological processing is a core component of reading disability, we tested for late phonological effects. We focused on the NW vs. PW contrast, assuming that none have a lexical representation and the assembly of a new pronunciation will be more difficult for the first NW stimulus type.

$N 320$ (310-350 ms). A late negative response around 310-350 ms was generated at temporal and temporo-parietal locations by pseudowords and nonwords. The repeated-measure ANOVA 


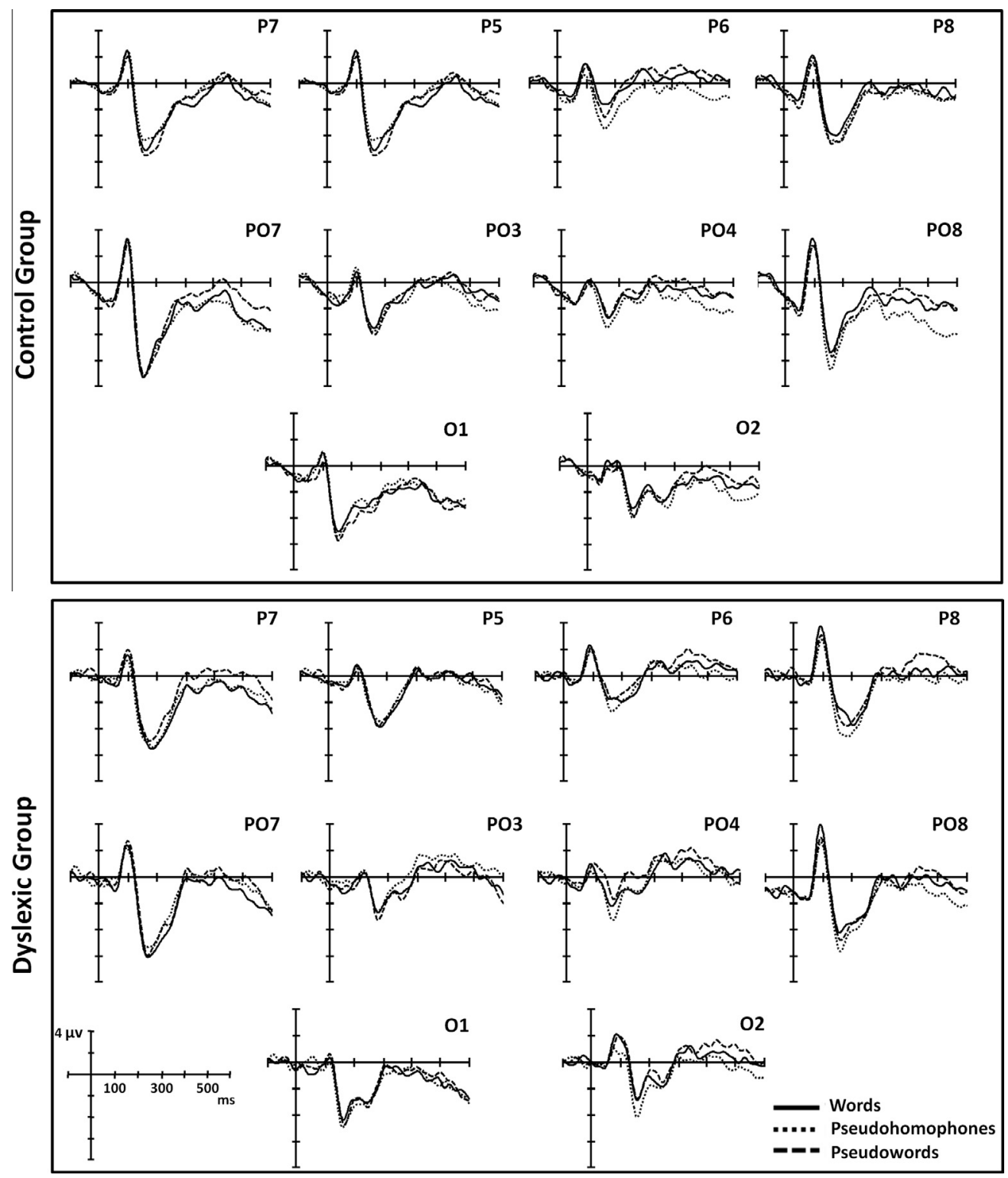

Fig. 4. ERP waveforms from representative electrodes for real words (solid line), pseudohomophones (dotted line), and pseudowords (dashed line), averaged separately for normal readers and dyslexics.

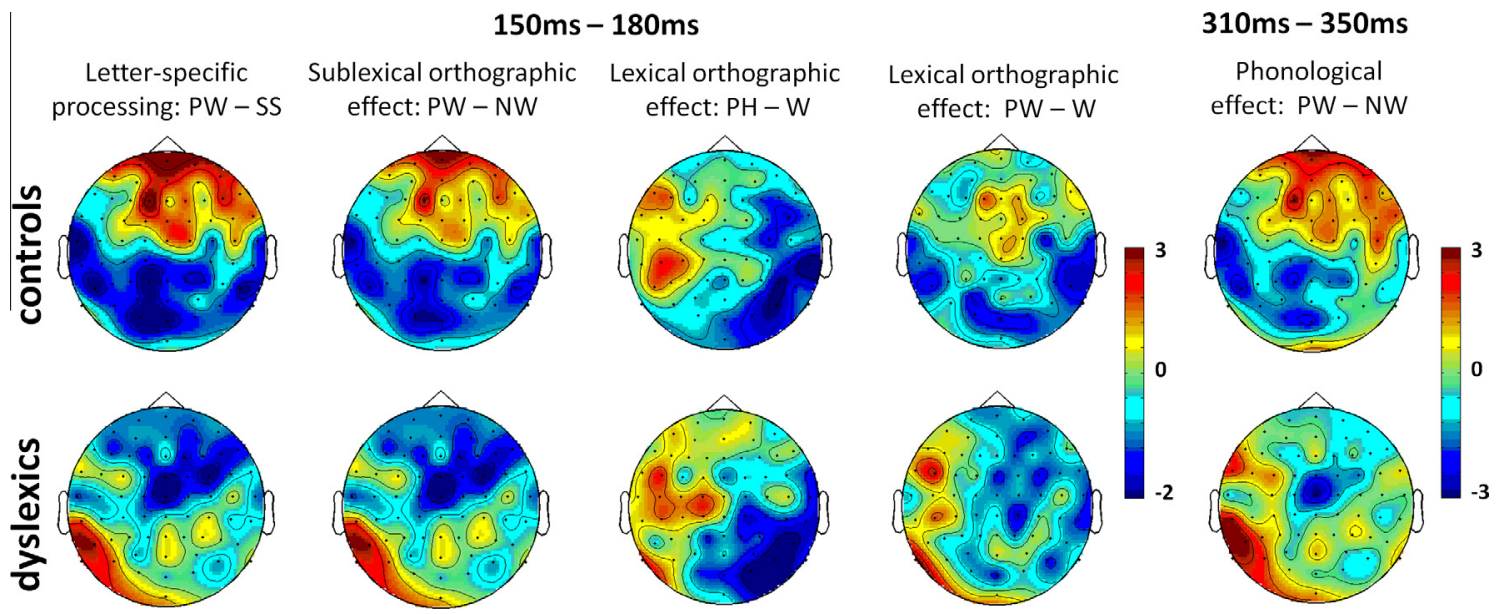

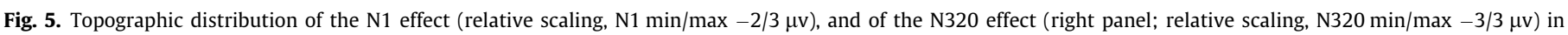
control and dyslexics readers. 
showed a significant main effect of hemisphere in the N320 window $(F(1,29)=5.0, p=.033)$ with ERPs being more negative over the left than the right hemisphere. More importantly, we also observed a significant interaction between stimulus type and group $(F(1,29)$ $=4.6, p=.040$ ). For the control group only, there were significant differences between PW and NW, with PW eliciting more negativegoing potentials than NW $(p=.059)$, most evident at the left hemisphere (Fig. 5).

We also observed that between 180 and $220 \mathrm{~ms}$ and the N320 to the stimulus, a positive component peaking around $300 \mathrm{~ms}$ was elicited, being larger for NW than for PW. It is possible that this response corresponds to the P300-family; previous studies have shown that infrequent and surprising events are associated with the P300-family (e.g., Ziegler, Besson, Jacobs, Nazir, \& Carr, 1997). Because our investigation focused on the early stages of word recognition (with some interest on later effects relating to phonology), we choose not to investigate this effect in more detail.

\section{Discussion}

The main aim of this study was to contribute to the debate over the specificity in orthographic processing and coding as indexed by the early $\mathrm{N} 1$ and $\mathrm{P} 1$ electrophysiological components of visual word recognition. The present conceptualization of orthographic coding considers both "coarse" (letter or letter-strings level) and "fine-print tuning" (sublexical and whole-word levels), manipulated here through different stimulus types (symbol strings, real words, pseudohomophones, pseudowords and nonwords). We also tested individuals varying in reading competence. The study of skilled and impaired dyslexic readers provides a good opportunity to investigate the interactions between neurobiological and reading expertise factors on the functional organization of the brain, particularly the visual word recognition system.

Our first hypothesis was that a specific brain training effect for letter processing in adults, the N1 "coarse tuning for letter strings", would be found for letter strings when contrasted with non-orthographic symbols (for brevity, we only focused on the difference between pseudowords and symbol-sequences), at least for the typical readers. This would replicate previous experiments (e.g., Maurer et al., 2005, 2007), and claims that N1 is a robust neurophysiological marker for fast specialization for letter strings. While both groups differentiated between stimulus types, somewhat surprisingly, in our study the activation elicited by symbol-sequences was greater than activation elicited by pseudowords during the time range from 150 to $180 \mathrm{~ms}$ (N1 component). On the background of previous research (e.g., Brem et al., 2009; Maurer et al., $2005,2006)$, the inversed pattern was rather expected, i.e. stronger response to orthographic stimulation. A significant difference between our paradigm and the one used in a previous study on children (Araújo et al., 2012) relates to the stimulus length: in Araújo et al. the symbol strings consisted of 3-5 symbols - and here a typical effect of greater N1 amplitudes for letter strings than for symbols was obtained. In the current study strings are considerably longer, varying between 4 and 8 symbols; the symbols that were used in both studies were the same. This difference in length could have resulted in a harder task - our participants took longer to respond to symbols, while in Araújo et al. no stimulus type effect was observed on RTs - and therefore in a larger N1 component. This suggests a greater perceptual resource allocation for symbols than for letter strings, and is consistent with the fact that the N1 component is an index of perceptual processing: Increased visual processing demands are reflected by more negative values (e.g., Johnson \& Olshausen, 2003; Kiefer, 2001; Tanaka, Luu, Weisbrod, \& Kiefer, 1999). Yet, visual inspection of Fig. 3 reveals that at the majority of posterior sites (e.g., PO3/PO4) the N1 response to pseudowords, although weaker, tends to peak slightly earlier than the response to symbol-sequences and this effect is more clearly present over the left hemisphere. In addition, similarly to previous studies (e.g., Maurer et al., 2005, 2011), pseudowords and symbolsequences evoked responses already in the earlier P1 component, reflecting that letter-specific processing in adults is under way as early as $80-120 \mathrm{~ms}$. Taken together, the observed ERP activity is compatible with the idea that reading acquisition, and skilled processing of letters, drives the emergence of a perceptual mechanism specifically attuned to the properties of the orthographic code, signaled by the P1/N1 electrophysiological response (Brem et al., 2009; Maurer et al., 2005, 2006; McCandliss et al., 2003). We note that in earlier ERP studies using false-font instead to better control for low-level visual differences with letters, print tuning effects were still robust (Eberhard-Moscicka et al., 2014), suggesting that the effects shown in studies using symbol strings are not due to low-level differences.

With respect to dyslexia, research has suggested that the N1response is a neural correlate of the disorder, based on absent differences in electrophysiological responses to words vs. symbol strings (Araújo et al., 2012; Hasko et al., 2013; Helenius et al., 1999; Mahé et al., 2012). Some have been acknowledged that dysfunctions are critical already at the letter level (Kronschnabel, Schmid, Maurer, \& Brandeis, 2013; Maurer et al., 2007). However, these findings were not replicated in our sample since the early ERP components (P1 and N1) were similarly modulated in the two reading groups. Only the behavioral data resembled a reduced visual expertise/specialization for orthographic material in dyslexia: our dyslexic participants processed similarly across conditions whereas controls took longer to respond to symbol strings compared with all the orthographic items.

We turn now to the main focus of the present study: by manipulating different dimensions of orthographic processing tapped into by four-letter string conditions (W, PH, PW, NW) enabled us to further confine the P1-N1 specialization. Early in visual word recognition, a mental orthographic representation of the observed string is built, this representation being shaped by the dependencies among letters in word-forms that reflect orthographic structure (for example, which letters are likely to co-occur in the language). Based on this, the present study analyzed whether the early P1/N1 evoked responses would be sensitive to the sublexical orthographic structure of words, through the comparison between orthographically legal (pseudowords) and orthographically illegal (nonwords) nonlexical items. The ERP analysis of the P1 component showed activation differences only for skilled readers. Likewise, a significant effect was detected for the N1 response in this group, with increased left-lateralized negativity to pseudowords than to nonwords. It thus seems that the adult's brain is sensitive to the dependencies among letters and positions within word-forms (sublexical orthographic units) in a very early stage of the reading process, as early as $80-120 \mathrm{~ms}$ after stimulus onset. Recent studies have already suggested neurophysiological correlates of sublexical orthographic processing in similar latency ranges (Coch \& Mitra, 2010; Hauk, Davis, Ford, Pulvermüller, \& Marslen-Wilson, 2006; Hauk et al., 2006), although using other measures of orthotactic constrains like tri-/bigram frequency. Our results add to these studies indicating that orthographic typicality assessed both in terms of letter position frequency and sequential constraints can modulate early ERP responses of visual word recognition.

Remarkably, unlike controls, the P1 and N1 mean amplitudes did not discriminate between orthographically legal and orthographically illegal material in readers with dyslexia. Absence of pseudoword-nonword differences suggests deviations in the early brain activation related to sublexical orthographic analysis and processing. This is an interesting result since previous research on dyslexia has mainly assessed the outcome of the learning process, that is, word-specific knowledge. Thus, findings of dyslexic 
impaired orthographic processing (e.g., Araújo et al., 2014; Bergmann \& Wimmer, 2008) might at least in part be driven by sublexical orthographic cues which are processed less efficiently in these readers. As visual processing is expected to feed information forward to more anterior regions that begin to activate word representations candidates (see for example, Dehaene, 2010), it is possible that sublexical orthographic processing abnormalities in readers with dyslexia may impact the efficiency of later lexical stages.

As another dimension of orthographic processing, in this study we also investigated the N1 sensitivity to whole-word orthography. The research on this topic is rather mixed: some studies have found distinct neurophysiological manifestations between pseudowords and words (Hauk, Coutout, Holden, \& Chen, 2012; Hauk, Pulvermuller, Ford, Marslen-Wilson, \& Davis, 2009; Hauk et al., 2006; Taroyan \& Nicolson, 2009), and significant effects of frequency (Hauk \& Pulvermuller, 2004; Sereno, Brewer, \& O'Donnell, 2003; Sereno et al., 1998), while others have reported no effect of lexicality or frequency in the N1 time window (Araújo et al., 2012; Hasko et al., 2013; Maurer et al., 2005), suggesting therefore that lexical access is located later on in processing. In this study we manipulated the variable orthographic lexicality (words vs. pseudowords) as a property of the word as a whole, and also compared the N1-evoked response to pseudohomophones as a way to minimize phonological familiarity confound. A stimulus-dependent dissociation between the cerebral hemispheres was observed. For both reading groups, pseudohomophones elicited greater activation than did orthographically familiar words and also pseudowords at the right posterior sites. Pseudohomophones sound like real words but are spelled incorrectly, which means that their phonological representations do not match the orthographic representations in memory (unlike words and pseudowords). Therefore, we interpret our ERP results as likely reflecting the brain electrical response to the conflict between stored orthographic and phonological information. This would mean that even early in processing, visual-orthographic information and phonological information begin to interact (see also, for example, Braun, Hutzler, Ziegler, Dambacher, \& Jacobs, 2009). Data is thus more compatible with a conceptualization of reading as an interactive processing system whereby higher-level linguistic information, not necessarily orthographic, modulates early orthographic processing (for a recent review see Carreiras, Armstrong, Perea, \& Frost, 2014). Interestingly, such modulation was similar in readers with dyslexia (who also showed amplified responses to pseudohomophones), which suggests that early sensitivity or access to phonological information per se is not the main locus of phonological dysfunction in dyslexia (see also Savill \& Thierry, 2011a).

Meanwhile, at the left occipital electrodes real words produced smaller negativity of the N1 compared to pseudohomophones and pseudowords, which did not differ from one another. As only words possess an entry in the orthographic mental lexicon, we interpret these activation differences as evidence that at this point in time some lexical orthographic processes are, probably, taking place already. From a dual-route perspective of reading (Coltheart, 2007; Coltheart, Rastle, Perry, Langdon, \& Ziegler, 2001), less effort was expected in order to find a fitting orthographic representation for familiar words in the orthographic lexicon, whereas the search should be prolonged and unsuccessful in case of unfamiliar word-forms, resulting in enhanced N1-amplitudes to pseudohomophones and pseudowords as found by us. Here the finding that lexical variables affect the brain response very early in processing fits better within frameworks where word recognition is accomplished by early near-simultaneous (cascaded) or partially overlapping stages and the underlying processes can be interactive (e.g., o Grainger \& Holcomb, 2009; Pulvermüller, Shtyrov, \& Hauk, 2009). Accordingly, in a study using a multiple regression design Hauk, Davis et al. (2006) reported an early lexical frequency effect around $110 \mathrm{~ms}$ that closely follows and partly overlaps with the earlier bigram frequency effect.

But how could we reconcile the diverging findings across studies? One possibility has to do with developmental aspects. Most of the studies reporting null lexicality or frequency effects were conducted in the early reading stages of reading development (e.g., in ten-year-old children, Araújo et al., 2012; in eight-year-old children, Hasko et al., 2013). Presumably, when the reading process is not yet fully automatized (as in young children) N1 is likely an index of pre-lexical processing only, but with increasing reading expertise (adults) it might reflect sensitivity to lexical orthographic information as well.

On the other hand, the dyslexic adults examined here had similar orthographic familiarity effects. We argue that early lexical orthographic access for known words in our sample may not have been deficient, though this output would seem particularly true for high-functioning adults with dyslexia. Several FMRI studies in children have reported that dyslexics when compared to skilled readers failed to exhibit a VWFA specialization at the higher wholeword level, showing similar activity for orthographic unfamiliar and familiar word-forms (the so-called orthographic familiarity effect; van der Mark et al., 2009; see also Cao, Bitan, Chou, Burman, \& Booth, 2006). Recently, using ERPs Hasko, Bruder, Bartling, and Schulte-Körne (2012) suggested that even if dyslexics may possess intact orthographic entries, the integration of orthographic and phonological representations appears deficient in these individuals (as indexed by the N300 component).

Lastly, in our study we further analyzed ERP measures associated with phonological processing (N320 component), given that our paradigm provides also a good opportunity to investigate online phonological processing and that impairments at this level represent a core feature in dyslexia (e.g., Ramus et al., 2003). We predicted that for normal readers (unlike dyslexics) pseudowords and nonwords would also differentiate on later latencies corresponding to the N320 component, which is believed to reflect phonological processes (Bentin et al., 1999; Simon et al., 2004). As expected, an increased left temporal and temporo-parietal negativity occurring at 310-350 ms (N320) was observed for normal readers in response to pseudowords. This N320 response might be explained by intrinsic differences in the processing operations that occur: the frequency of occurrence of the pseudowords' sound structure (i.e., the phonotactic probability in the language) is higher than that for nonwords - for these the assembly of a new pronunciation would presumably be more difficult - and thus pseudowords would benefit more from phonological recoding for maintaining stimuli in working memory (e.g., phonological loop, Baddeley, 1986; see also Ziegler \& Jacobs, 1995). Note that our participants have to keep the entire letter sequences in working memory until they knew what the target letter was. Similar N320 modulations were obtained in children, comparing pseudowords and unpronounceable consonant-strings (Araújo et al., 2012).

No ERP differences were, however, observed in the dyslexic group between pseudowords and nonwords during the N320 time window. This result is consistent with those obtained on other explicit phonological awareness measures, most of which are in the N400 range (e.g., auditory and visual rhyming; Ackerman, Dykman, \& Oglesby, 1994; McPherson \& Ackerman, 1999; McPherson, Ackerman, Holcomb, \& Dykman, 1998; Rüsseler, Becker, Johannes, \& Münte, 2007; see also Jednoróga, Marchewkaa, Tacikowskia, \& Grabowska, 2010). It is also compatible with the hypothesis that dyslexics fail to adequately develop phonological skills, as well as an under-activation of temporo-parietal areas (Georgiewa et al., 2002; Shaywitz et al., 2001; see Richlan, Kronbichler, \& Wimmer, 2009, for a review) or less engagement of the left hemisphere in these readers (e.g., Araújo 
et al., 2012; Pugh et al., 2000; Shaywitz et al., 2001). Yet, it might be the case that these modulations of the N320 (and N400) reflect effects that are too late to index impaired perceptual sensitivity to phonology (cf., Savill \& Thierry, 2011b), and therefore index something else. These effects are probably more compatible with recent accounts of mechanisms that contribute to phonological dysfunction, involving integration/working memory during phonological analysis (e.g., Ramus \& Szenkovits, 2008). Furthermore, the complementary phonological tasks in this study (see Table 1) clearly showed that normal-readers outperform dyslexics.

It is plausible that the early (N1) and the late (N320) betweengroup ERP differences in our study are somehow related to the significant differences in behavioral data. However, we believe this is unlikely for several reasons. First, behavioral effects cannot be attributed to other skills than reading. For example, the groups did not differ with respect to important parameters such as IQ (see Table 1) and general processing speed, measured here by the WAIS coding subtask $(p>.2)$. In terms of behavioral data, despite the fact that the dyslexic group was generally slower to respond than the controls, the interaction between Group and Condition was non-significant in the RT analysis, which means that their delay in performance was affected to the same extent in all the experimental conditions. Hence, it seems unlikely that the interactions Group by Condition obtained in the ERP analysis may be the result of underlying general differences in cognitive speed rather than of specific effects due to the experimental manipulations. Also note that a re-analysis of the $\mathrm{N} 1$ effect after adjusting the time window centered on $\mathrm{N} 1$ peak to $165-195 \mathrm{~ms}$ (based o visual inspection) for the dyslexic group (to still account for the possibility that the $\mathrm{N} 1$ might be delayed for dyslexics compared to controls), yielded the same pattern of results.

\section{Conclusion}

This study provides evidence for early brain sensitivity $(\sim 150-$ $180 \mathrm{~ms}$ ) to the structure of orthographic word-forms: N1 component (and also P1) reflects analysis of sublexical orthographic units tapped into by complex dependencies among letters and positions within each word. However, if reading skills develop insufficiently (as in dyslexia), subjects' brain apparently fail to properly attune to these complex features of the visual word-form. On the other hand, lexicality variables were reflected in early brain responses as well. For adults at least, N1 may already index the searching process for an orthographic representation in the lexicon (reduced amplitude responses for known words), and taken together data argue in favor of early near-simultaneity or even partial overlap of processing stages during visual word recognition. Also, the results raise the possibility that the recognition of printed words is constrained by phonology (enhanced ERPs to pseudohomophones). Finally, we interpreted lacking N320 modulation in dyslexic participants as a deficit in the later phonological processing stages, perhaps relating to some form of reduced maintenance and integration of phonological information rather than to early phonological extraction from orthography.

\section{Acknowledgments}

This work was supported by national Portuguese funding through FCT - Fundação para a Ciência e Tecnologia, project reference SFRH/BPD/72974/2010, PTDC/PSI/110734/2009, and PEst-OE/ EQB/LA0023/2013, as well as Max Planck Institute for Psycholinguistics, Donders Institute for Brain, Cognition and Behaviour, Radboud University Nijmegen, and the Swedish Dyslexia Foundation. The authors also thank Artur de Lara for his help with data collection.

\section{References}

Ackerman, P. T., Dykman, R. A., \& Oglesby, D. M. (1994). Visual event related potentials of dyslexic children to rhyming and nonrhyming stimuli. Journal of Clinical and Experimental Neuropsychology, 16, 138-154.

Alves, R. A. \& Castro, S. L. (2004). Adult dyslexia screening using a Portuguese selfreport measure. In Paper presented at the $2^{\circ}$ Congresso Hispano-Português de Psicologia, Universidade de Lisboa.

Alves, R. A., Branco, M., Pontes, A., \& Castro, S. L. (2007). Avaliação das dificuldades de leitura e escrita: Desenvolvimento da Bateria Fonológica da Universidade do Porto (Assessment of reading and spelling problems: Development of Porto's phonological assessment battery). Educação: Temas e Problemas, 4, 203-222.

Araújo, S., Faísca, L., Bramão, I., Petersson, K. M., \& Reis, A. (2012) Electrophysiological correlates of impaired reading in dyslexic pre-adolescent children. Brain and Cognition, 79, 79-88.

Araújo, S., Faísca, L., Bramão, I., Petersson, K. M., \& Reis, A. (2014). Lexical and phonological processes in dyslexic readers: Evidence from a visual lexical decision task. Dyslexia, 20, 38-53.

Assadollahi, R., \& Pulvermuller, F. (2003). Early influences of word length and frequency: A group study using MEG. NeuroReport, 14(8), 1183-1187.

Bacelar do Nascimento, M. F., Casteleiro, J. M., Marques, M. L. G., Barreto, F., Amaro, R., \& Veloso, R. (2007). Corlex: Léxico multifuncional computorizado do Português contemporâneo (lmcpc_dec.txt) <http://www.clul.ul.pt/sectores/ linguistica_de_corpus/projecto_lmcpc.php> Retrieved from Centro de Linguística da Universidade de Lisboa.

Baddeley, A. D. (1986). Working memory. UK: Clarendon Press.

Bentin, S., Mouchetant-Rostaing, Y., Giard, M. H., Echallier, J. F., \& Pernier, J. (1999). ERP manifestations of processing printed words at different psycholinguistic levels: Time course and scalp distribution. Journal of Cognitive Neuroscience, 11 (3), 235-260.

Bergmann, J., \& Wimmer, H. (2008). A dual-route perspective on poor reading in a regular orthography: Evidence from phonological and orthographic lexical decisions. Cognitive Neuropsychology, 25(5), 653-676.

Blomert, L., \& Vaessen, A. (2009). Differentiaal Diagnostiek van Dyslexie; Cognitieve analyse van lezen en spellen [Dyslexia Differential Diagnosis; cognitive analysis of reading and spelling]. Amsterdam: Boom test publishers B.V.

Boets, B., Op de Beeck, H. P., Vandermosten, M., Scott, S. K., Gillebert, C. R., et al (2013). Intact but less accessible phonetic representations in adults with dyslexia. Science, 342, 1251-1254.

Braun, M., Hutzler, F., Ziegler, J. C., Dambacher, M., \& Jacobs, A. M. (2009) Pseudohomophone effects provide evidence of early lexico-phonological processing in visual word recognition. Human Brain Mapping, 30, 1977-1989.

Brem, S., Bach, S., Kucian, K., Guttorm, T. K., Martin, E., Lyytinen, H., et al. (2010). Brain sensitivity to print emerges when children learn letter-speech sound correspondences. Proceedings of the National Academy of Sciences of the United States of America, 107(17), 7939-7944.

Brem, S., Halder, P., Bucher, K., Summers, P., Martin, E., \& Brandeis, D. (2009). Tuning of the visual word processing system: Distinct developmental ERP and fMRI effects. Human Brain Mapping, 30(6), 1833-1844.

Burt, J. S. (2006). What is orthographic processing skill and how does it relate to word identification in reading? Journal of Research in Reading, 29(4), 400-417.

Cao, F., Bitan, T., Chou, T., Burman, D. D., \& Booth, J. R. (2006). Deficient orthographic and phonological representations in children with dyslexia revealed by brain activation patterns. Journal of Child Psychology and Psychiatry, 47(10) 1041-1050.

Carreiras, M., Armstrong, B. C., Perea, M., \& Frost, R. (2014). The what, when, where and how of visual word recognition. Trends in Cognitive Sciences, 18(2), 90-98.

Coch, D., \& Mitra, P. (2010). Word and pseudoword superiority effects reflected in the ERP waveform. Brain Research, 1329, 159-174.

Cohen, L., Lehericy, S., Chochon, F., Lemer, C., Rivaud, S., \& Dehaene, S. (2002). Language-specific tuning of visual cortex functional properties of the visual word form area. Brain, 125, 1054-1069.

Coltheart, M., Rastle, K., Perry, C., Langdon, R., \& Ziegler, J. C. (2001). DRC: A dual route cascaded model of visual word recognition and reading aloud. Psychological Review, 108(1), 204-256.

Coltheart, M. (2007). Modeling reading: The dual-route approach. In M. J. Snowling \& C. Hulme (Eds.), The science of reading: A handbook (pp. 6-23). UK: Blackwell Publishing.

Dehaene, S. (2010). Reading in the brain: The new science of how we read. UK: Penguin Book.

Dehaene, S., Pegado, F., Braga, L. W., Ventura, P., Filho, G. N., Jobert, A., et al. (2010). How learning to read changes the cortical networks for vision and language. Science, 330, 1359-1364.

Eberhard-Moscicka, A. K., Jost, L. B., Raith, M., \& Maurer, U. (2014). Neurocognitive mechanisms of learning to read: Print tuning in beginning readers related to word-reading fluency and semantics but not phonology. Developmental Science, $1-13$.

Francisco, A. \& Faísca, L. (2012). Bidirectional association between vocabulary and phonology? A correlational study. In Paper presented at the abstract book of the VII meeting of the Portuguese society of experimental psychology, University of Lisboa.

Georgiewa, P., Rzanny, R., Gaser, C., Gerhard, U., Vieweg, U., Freesmeyer, D., et al. (2002). Phonological processing in dyslexic children: A study combining functional imaging and event related potentials. Neuroscience Letters, 318, 5-8. 
Grainger, J., \& Holcomb, P. J. (2009). Watching the word go by: On the time-course of component processes in visual word recognition. Language and Linguistics Compass, 3(1), 128-156.

Hagiliassis, N., Pratt, C., \& Johnston, M. (2006). Orthographic and phonological processes in reading. Reading and Writing, 19, 235-263.

Hasko, S., Bruder, J., Bartling, J., \& Schulte-Körne, G. (2012). N300 indexes deficient integration of orthographic and phonological representations in children with dyslexia. Neuropsychologia, 50, 640-654.

Hasko, S., Groth, K., Bruder, J., Bartling, J., \& Schulte-Körne, G. (2013). The time course of reading processes in children with and without dyslexia: An ERP study. Frontiers in Human Neuroscience, 7, 570.

Hauk, O., Coutout, C., Holden, A., \& Chen, Y. (2012). The time-course of single-word reading: Evidence from fast behavioral and brain responses. NeuroImage, 60 $1462-1477$.

Hauk, O., Davis, M. H., Ford, M., Pulvermüller, F., \& Marslen-Wilson, W. D. (2006) The time course of visual recognition as revealed by linear regression analysis of ERP data. Neuroimage, 30, 1383-1400.

Hauk, O., Patterson, K., Woollams, A., Watling, L., Pulvermüller, L., \& Rogers, T. T. (2006). [Q:] When would you prefer a SOSSAGE to a SAUSAGE? [A:] At about $100 \mathrm{~ms}$. ERP correlates of orthographic typicality and lexicality in written word wecognition. Journal of Cognitive Neuroscience, 18(5), 818-832.

Hauk, O., \& Pulvermuller, F. (2004). Effects of word length and frequency on the human event-related potential. Clinical Neurophysiology, 115, 1090-1103.

Hauk, O., Pulvermuller, F., Ford, M., Marslen-Wilson, W. D., \& Davis, M. H. (2009). Can I have a quick word? Early electrophysiological manifestations of psycholinguistic processes revealed by event-related regression analysis of the EEG. Biological Psychology, 80(1), 64-74.

Hawelka, S., Gagl, B., \& Wimmer, H. (2010). A dual-route perspective on eye movements of dyslexic readers. Cognition, 115, 367-379.

Helenius, P., Tarkiainen, A., Cornelissen, P. L., Hansen, P. C., \& Salmelin, R. (1999) Dissociation of normal feature analysis and deficient processing of letter-strings in dyslexic adults. Cerebral Cortex, 9, 476-483.

Jednoróga, K., Marchewkaa, A., Tacikowskia, P., \& Grabowska, A. (2010). Implicit phonological and semantic processing in children with developmental dyslexia: Evidence from event-related potentials. Neuropsychologia, 48, 2447-2457.

Johnson, J., \& Olshausen, B. (2003). Time course of neural signatures of object recognition. Journal of Vision, 3, 499-512.

Kast, M., Elmer, S., Jancke, L., \& Meyer, M. (2010). ERP differences of pre-lexical processing between dyslexic and non-dyslexics children. International Journal of Psychophysiology, 77, 59-69.

Kiefer, M. (2001). Perceptual and semantic sources of category-specific effects: Event-related potentials during picture and word categorization. Memory and Cognition, 29, 100-116.

Kronschnabel, J., Schmid, R., Maurer, U., \& Brandeis, D. (2013). Visual print tuning deficits in dyslexic adolescents under minimized phonological demands. Neurolmage, 74, 58-69.

Lefly, D. L., \& Pennington, B. F. (2000). Reliability and validity of the adult reading history questionnaire. Journal of Learning Disabilities, 33, 286-296.

Mahé, G., Bonnefond, A., Gavens, N., Dufour, A., \& Doignon-Camus, N. (2012). Impaired visual expertise for print in French adults with dyslexia as shown by N170 tuning. Neuropsychologia, 50(14), 3200-3206.

Marinelli, C. V., Angelelli, P., Notarnicola, A., \& Luzzatti, C. (2009). Do Italian dyslexic children use the lexical reading route efficiently? An orthographic judgment task. Reading and Writing, 22, 333-351.

Marinus, E., \& de Jong, P. F. (2010). Size does not matter, frequency does: Sensitivity to orthographic neighbors in normal and dyslexic readers. Journal of Experimental Child Psychology, 106, 129-144.

Maurer, U., Blau, V. C., Yoncheva, Y. N., \& McCandliss, B. D. (2010). Development of visual expertise for reading: Rapid emergence of visual familiarity for an artificial script. Developmental Neuropsychology, 35(4), 404-422.

Maurer, U., Brem, S., Bucher, K., \& Brandeis, D. (2005). Emerging neurophysiologica specialization for letter strings. Journal of Cognitive Neuroscience, 17(10), 1532-1552.

Maurer, U., Brem, S., Bucher, K., Kranz, F., Benz, R., Steinhausen, H., et al. (2007). Impaired tuning of a fast occipito-temporal response for print in dyslexic children learning to read. Brain, 130, 3200-3210.

Maurer, U., Brem, S., Kranz, F., Bucher, K., Benz, R., Halder, P., et al. (2006). Coarse neural tuning for print peaks when children learn to read. Neurolmage, 33, $749-758$.

Maurer, U., \& McCandliss, B. D. (2007). The development of visual expertise for words: The contribution of electrophysiology. In E. L. Grigorenko \& A. J. Naples (Eds.), Single-word reading: Biological and behavioral perspectives. Mahwah, NJ: Lawrence Erlbaum Associates.

Maurer, U., Schulz, E., Brem, S., der Mark, S. V., Bucher, K., Martin, E., et al. (2011). The development of print tuning in children with dyslexia: Evidence from longitudinal ERP data supported by fMRI. Neuroimage, 57, 714-722.
McCandliss, B. D., Cohen, L., \& Dehaene, S. (2003). The visual word form area: Expertise for reading in the fusiform gyrus. Trends in Cognitive Sciences, 7 293-299.

McPherson, W. B., \& Ackerman, P. T. (1999). A study of reading disability using event-related brain potentials elicited during auditory alliteration judgments. Developmental Neuropsychology, 15(3), 359-378.

McPherson, W. B., Ackerman, P. T., Holcomb, P. J., \& Dykman, R. A. (1998). Eventrelated brain potentials elicited during phonological processing differentiate subgroups of reading disabled adolescents. Brain and Language, 62, 163-185.

Oostenveld, R., Fries, P., \& Jensen, O. (2009). Fieldtrip toolbox <http://www.ru.nl/ fcdonders/fieldtrip>.

Pugh, K. R., Mencl, W. E., Jenner, A. R., Katz, L., Frost, S. J., Lee, J. R., et al. (2000). Functional neuroimaging studies of reading and reading disability (developmental dyslexia). Mental Retardation Developmental Disabilities Research Reviews, 6, 207-213.

Pulvermüller, F., Shtyrov, Y., \& Hauk, O. (2009). Understanding in an instant: Neurophysiological evidence for mechanistic language circuits in the brain. Brain \& Language, 110, 81-94.

Ramus, F., Rosen, S., Dakin, S. C., Day, B. L., Castellote, J. M., White, S., et al. (2003). Theories of developmental dyslexia: Insights from a multiple case study of dyslexic adults. Brain, 126, 841-865.

Ramus, F., \& Szenkovits, G. (2008). What phonological deficit? The Quarterly Journal of Experimental Psychology, 61(1), 129-141.

Richlan, F., Kronbichler, M., \& Wimmer, H. (2009). Functional abnormalities in the dyslexic brain: A quantitative meta-analysis of neuroimaging studies. Human Brain Mapping, 30, 3299-3308.

Richlan, F., Sturm, D., Schurz, M., Kronbichler, M., Ladurner, G., \& Wimmer, H (2010). A common left occipito-temporal dysfunction in developmental dyslexia and acquired letter by letter reading? PLOS ONE, 5, e12073.

Rüsseler, J., Becker, P., Johannes, S., \& Münte, T. F. (2007). Semantic, syntactic, and phonological processing of written words in adult developmental dyslexic readers: An event-related brain potential study. BMC Neuroscience, 8, 1-10.

Savill, N. J., \& Thierry, G. (2011a). Electrophysiological evidence for impaired attentional engagement with phonologically acceptable misspellings in developmental dyslexia. Frontiers in Psychology, 2, 1-16.

Savill, N. J., \& Thierry, G. (2011b). Reading for sound with dyslexia: Evidence for early orthographic and late phonological integration deficits. Brain Research, $1385,192-205$.

Schutter, D. J. L. G., Leitner, C., Kenemans, J. L., \& van Honk, E. J. (2006). Electrophysiological correlates of cortico-subcortical interaction: A crossfrequency spectral EEG analysis. Clinical Neurophysiology, 117, 381-387.

Sereno, S. C., Brewer, C. C., \& O’Donnell, P. J. (2003). Context effects in word recognition: Evidence for early interactive processing. Psychological Science, 14, 328-333.

Sereno, S. C., Rayner, K., \& Posner, M. I. (1998). Establishing a time-line of word recognition: Evidence from eye movements and event-related potentials. NeuroReport, 9, 2195-22200.

Shaywitz, B. A., Shaywitz, S. E., Pugh, K. R., Fulbright, R. K., Mencl, W. E., Constable, R. T., et al. (2001). The neurobiology of dyslexia. Clinical Neuroscience Research, 1, 291-299.

Simon, G., Bernard, C., Largy, P., Lalonde, R., \& Rebai, M. (2004). Chronometry of visual word recognition during passive and lexical decision tasks: An ERP investigation. International Journal of Neuroscience, 114, 1401-1432.

Tanaka, J., Luu, P., Weisbrod, M., \& Kiefer, M. (1999). Tracking the time course of object categorization using event-related potentials. NeuroReport, 10, 829-835.

Tarkiainen, A., Helenius, P., Hansan, P. C., Cornelissen, P. L., \& Salmelin, R. (1999). Dynamics of letter string perception in the human occipitotemporal cortex. Brain, 122, 2119-2131.

Taroyan, N. A., \& Nicolson, R. I. (2009). Reading words and pseudowords in dislexia: ERP and behavioural tests in English-speaking adolescents. International Journal of Psychophysiology, 74, 199-208.

van der Mark, S., Bucher, K., Maurer, U., Schulz, E., Brem, S., Buckelmüller, J., et al. (2009). Children with dyslexia lack multiple specializations along the visual word-form (VWF) system. Neurolmage, 47, 1940-1949.

Venkatagiri, H. S., \& Levis, J. M. (2007). Phonological awareness and speech comprehensibility: An exploratory study. Language Awareness, 16(4), 263-277.

Wimmer, H., Schurz, M., Sturm, D., Richlan, F., Klack, J., Kronbichler, M., et al. (2010). A dual-route perspective on poor reading in a regular orthography: An fMRI study. Cortex, 46, 1284-1298.

Ziegler, J. C., Besson, M., Jacobs, A. M., Nazir, T. A., \& Carr, T. H. (1997). Word, pseudoword, and nonword processing: A multitask comparison using eventrelated brain potentials. Journal of Cognitive Neuroscience, 9(6), 758-775.

Ziegler, J. C., \& Jacobs, A. M. (1995). Phonological information provides early sources of constraint in the processing of letter strings. Journal of Memory and Language, 34, 567-593. 